\title{
Os saberes das águas no ensino de ciências: intertrocas de conhecimentos e pessoas
}

\section{Water knowledge in science education: exchanging of knowledge and people}

\author{
Eliene da Silva Alves (elienyalves@hotmail.com) \\ Universidade Federal do Pará (UFPA), Faculdade de Etnodiversidade \\ Eliana Campos Pojo Toutonge (elianapojo@ufpa.br) \\ Universidade Federal do Pará (UFPA), Faculdade de Educação e Ciências Sociais
}

Resumo: O artigo discute os 'saberes das águas' no ensino de ciências na rede municipal de ensino do Acará (PA), considerando as intertrocas socioculturais, os aprendizados do cotidiano e as relações que estabelecem no espaço das águas por moradores residentes às margens do rio Acará. Trata-se de uma pesquisa em andamento, balizada por estabelecer relações entre os saberes das águas e possíveis temáticas a serem trabalhadas no ensino de ciências. O estudo de caráter qualitativo, cujos procedimentos metodológicos envolvem observação participante, entrevistas e registros do cotidiano do entorno do rio Acará junto aos sujeitos envolvidos. Soma-se, ainda, o estudo bibliográfico a partir de Brandão (2007), Freire (1996), Diegues (2007), Castro (1998) e Sasseron (2017). São notórias as formas funcionais de movimentação dos sujeitos com as águas em suas vivências, sugerindo-nos intertrocas teóricas e metodológicas de produção de conhecimento. Como resultados parciais, é possível sinalizar que os saberes das águas são de ordem prática na vida dos sujeitos e, simultaneamente, relacionam-se com conhecimentos escolares, sendo uma oportunidade de estudo dos aspectos culturais e ambientais do lugar, a partir dos aprendizados dessa movimentação cotidiana que circulam nesse espaço.

Palavras-chave: Saberes locais e escolares. Vivências. Intertrocas. Rio Acará (PA).

\begin{abstract}
The article discusses the 'knowledge of the waters' in science teaching in the city school system of Acará (PA), considering the sociocultural exchanges, the daily learning and the relationships established in the water space by residents living on the riverside of the Acará river. This is a research in progress, marked by establishing relationships between water knowledge and possible themes to be worked on in science education. The qualitative study, whose methodological procedures involve participant observation, interviews and daily records of the surroundings of the Acará River with
\end{abstract}


the subjects involved. In addition, the bibliographic study from Brandão (2007), Freire (1996), Diegues (2007), Castro (1998) and Sasseron (2017). The functional forms of movement of the subjects with the water in their experiences are notorious, suggesting theoretical and methodological exchanges of knowledge production. As partial results, it is possible to signal that the knowledge of the waters are from practical nature in the subjects' lives and, simultaneously, they are related to school knowledge, being an opportunity to study the cultural and environmental aspects of the place, from the learning of this daily movement that surroundings the space.

Keywords: Local and school knowledge. Experiences. Interchanges. Acará River (PA).

\section{INTRODUÇÃO}

Os seres humanos, desde os primórdios, sempre estiveram interligados às fontes naturais, à flora, ao solo e à água que permanecem intensamente na vivência dos sujeitos. Contudo, atualmente está ocorrendo uma ressignificação na maneira de atuação desses seres humanos perante os elementos naturais, resultando cada vez mais em atos danosos da ação humana para com a natureza, em particular pela ampla conexão com o capitalismo na sociedade atual.

No tocante às águas, há uma elevada conexão entre ela e os sujeitos, assim "A água é fundamental para a existência dos seres bióticos, uma fonte hídrica essencial para a permanência dos humanos no espaço planetário”. Encontra-se, além disso, imbricada às relações sociais, culturais e naturais da humanidade (ALVES; POJO, 2020, p. 48).

Durante muitos anos as pessoas que residem em lugares nas proximidades das águas praticam ações interligadas com o "mundo das águas”. Realizam-se, portanto, movimentações nas margens de rios, córregos e igarapés, sendo uma vivência propiciadora de aprendizados dessas pessoas de acordo com “[...] a territorialidade e temporalidade regida pelas águas.” (POJO, 2017, p. 64).

Nesse sentido, os sujeitos possuem saberes das águas originados a partir da movimentação e do convívio preciso daqueles que residem nas suas margens, dos que trabalham fazendo percursos pelas águas, dos que transitam ou atravessam rotineiramente pelas águas. Tais sujeitos dominam habilidades e aprendizados que comportam suas ações e ao conviverem nestes espaços socializam e constroem seus fazeres, seus saberes, seus modos de agir e formas de integração com as fontes naturais. 
Com isso, compreender a relação humano-natureza, em uma perspectiva de cuidado e proteção para com as fontes naturais, faz parte de um aprendizado humano, e os espaços sociais de convívio são locais propícios para construção desse aprendizado. Dentre esses espaços está o ambiente escolar, lugar de partilha e construção de conhecimento, em especial, na área das ciências da natureza por meio do ensino de ciências, campo que deve retratar questões socioambientais e da natureza, podendo dialogar diretamente com as ações cotidianas e conceitos teóricos.

Desta forma, a tentativa deste escrito é o diálogo entre os saberes das águas e o ensino de ciências, cujo recorte perpassa considerações acerca de um currículo escolar mais amazônico. Com isso, percorre-se as intertrocas das pessoas e seus convívios com as águas, com as marés, com as constantes travessias de sujeitos nestes espaços de intertrocas de conhecimento, de relações e de aprendizados que se difundem. Sendo possível por meio dessa experiência, observar situações naturais, socioculturais, socioambientais da ação humana na natureza. No caso do rio Acará, entre alguns usos, e durante as várias movimentações que ocorrem nele se processam também "[...] os sistemas de intertrocas de pessoas, de bens e de mensagens [...]" (BRANDÃO, 2007, p.53). Ocorre, então, um múltiplo compartilhamento de experiências nesses espaços de movimentação sociocultural.

Com base nessa ideia, o escrito objetiva compreender as relações que se estabelecem entre os saberes das águas de sujeitos que transitam e residem às margens do rio Acará-PA e de possíveis temáticas a serem trabalhadas no ensino de ciências para o Ensino fundamental - anos finais, na perspectiva das intertrocas. O estudo percorre ainda os objetivos específicos: caracterizar os saberes das águas dos moradores do entorno do Rio Acará, pontuando aspectos da natureza do lugar; e indicar possibilidades metodológicas com os possíveis saberes das águas e da natureza para serem trabalhados no Ensino de Ciências.

\section{MATERIAL E MÉTODO}

A pesquisa, em andamento, caracteriza-se por estabelecer relações entre pessoas, saberes e experiências que se dão no curso das águas do rio Acará, nesta cidade de mesmo nome. A área de abrangência da investigação delimita-se no entorno do rio, cuja 
localização perpassa a movimentação de travessia da balsa e de oito balsinhas ${ }^{1}$, na rua principal que circunda as feiras do peixe e da verdura. Sendo que parte desse entorno fica do outro lado do rio (em frente à cidade), onde existe um grupo de moradores locais (responsáveis pela realização da comercialização e das travessias). Além disso, eles trabalham como barqueiros e desempenham outras atividades comuns na região.

Trata-se de uma pesquisa que lida com a vida humana e suas realidades culturais, sociais, educacionais e ambientais; mais ainda, situa-se em um território ribeirinho ditado por legislações próprias. Por isto, estamos dando a devida atenção ao código ético necessário, no sentido da autorização por meio de termo de consentimento dos sujeitos envolvidos para o uso dos dados que computam imagens, videogravações e outras formas de captação. Outrossim, assumimos o compromisso com a devolutiva dos resultados da pesquisa, acordado com as lideranças do entorno do rio Acará, sem contar no cuidado visando assegurar a confidencialidade e fidedignidade dos dados ${ }^{2}$.

Visando captar os processos, os saberes das águas, as representações sobre o viver no entorno do rio Acará - na perspectiva de apontar caminhos para o ensino de ciências no âmbito dessa temática, a pesquisa vem se desenvolvendo com base nos seguintes procedimentos metodológicos:

a) estudo bibliográfico - com o intuito de buscar subsídios para a análise dos dados empíricos, bem como para o aprofundamento da questão por intermédio de diferentes autoras e autores, em especial Brandão (2007) e Freire (1996) tratando das intertrocas, dos saberes e das indicações metodológicas; Diegues (2007) abordando as Águas; Castro (1998) referenciando o contexto ribeirinho e, ainda, Sasseron (2017) no que se refere ao ensino de ciências;

b) observação participante - sendo priorizada a apuração do movimento cotidiano com observações no entorno do rio Acará e, também, o estabelecimento de relações de proximidade com os sujeitos;

Balsinha: parte do vocabulário local utilizado para denominar embarcações de pequeno porte que transportam motocicletas e pessoas de uma margem a outra desse rio.

${ }^{2}$ Sobre a questão, consultamos o e-book intitulado "Ética e Pesquisa em Educação: subsídios", elaborado pela Anped, 2019 (p. 53; 130). 
c) diálogos informais ressoantes de escutas, percepção de gestos e expressões e interações - os interlocutores diretos são os sujeitos que residem e/ou trabalham no entorno do rio;

d) produção escrita e visual - ocorre mediante rodas de conversa com os participantes da pesquisa, resultando na construção de mapas, captura de imagens do lugar, croquis dos espaços (feira, balsa, embarcações etc.) e registros de processos interativos;

e) elaboração de uma rede temática capaz de visualizar o intercâmbio de saberes (popular e o escolar) - indica-se assim, conteúdos acerca da questão da água possíveis de serem trabalhados enquanto conhecimento científico e modos socioambientais. Nesse sentido, consideram-se os objetivos propostos para o ensino de ciências. Aqui, delimitase o esforço de mostrar o intercâmbio de saberes, destacando visões empíricas e o conhecimento científico, basilares de uma prática emancipatória como bem situa Freire (1979). Ele acredita que por esta prática educativa o sujeito "[...] compreende sua realidade, pode levantar hipóteses sobre o desafio dessa realidade e procurar soluções" (FREIRE, 1979, p. 16).

\section{RESULTADOS E DISCUSSÕES}

Os saberes e os aprendizados presentes nos locais de convívio seguem o fluxo de nossas vivências. Eles são compartilhados nos diferentes espaços sociais, inclusive no espaço escolar sendo que se compreende como educação o processo de ensinoaprendizagem adquirida pelo indivíduo ao longo da vida a partir de suas relações cotidianas (BRANDÃO, 2007; ALVES et al, 2020).

Assim, vale dizer que o ensino nos espaços externos "[...] proporcionam educação e o desenvolvimento da ciência e cultura." (ALVES et al, 2020, p.238) e o ensino escolar é uma parte importante no aprendizado e na formação humana. Esse diz respeito a uma relação interativa entre pessoas, isto é, sujeito-sujeito na perspectiva de "ler o mundo" e de transformar realidades, isto é, relação sujeito-mundo. Nesses termos, ensinar-aprender prescinde uma prática educativa libertadora, no sentido de que “Educar é substancialmente formar” (FREIRE, 1996, p.32).

Também, suscitar os saberes cotidianos refletidos e com apropriação do conhecimento científico potencializa “[...] a construção de relações entre práticas 
cotidianas e práticas para o ensino [...]", auxiliando o ensino de ciências de forma mais adensada com outras maneiras de se compreender os fenômenos naturais, e assim, “[...] utilizar esses modos de estruturar ideias e pensamentos para a análise de fenômenos e de situações a eles relacionadas e tomar suas decisões (quaisquer que sejam) considerando tais aportes" (SASSERON, 2018, p.1068). Tal forma pedagógica e educativa caminha em direção ao aprendizado dos estudantes em ciências mediado por saberes locais, buscando a produção do conhecimento e, como consequência, tem-se a sabedoria de utilizá-los na vivência em sociedade.

Nessa perspectiva, se dá valor aos saberes que chegam à escola pelo cotidiano dos alunos (saber popular, sendo parte da construção pedagógica pelo professor) e, de outro, a questão pedagógica é refletida do ponto de vista de como se aprende e se constrói conhecimento por parte de ambos: os alunos em movimento de produção e o docente, revisando e atualizando constantemente sua prática.

Como precedentemente assinalado, neste escrito a tentativa é apresentar a temática das águas em interlocução com as vivências cotidianas dos sujeitos, conduzindo-nos a reafirmar os saberes das águas. Pontualmente, destacamos alguns apontamentos iniciais da pesquisa em relação a esta temática enquanto possíveis caminhos para uma prática educativa de ciências no Ensino Fundamental (anos finais), com destaque para temas e eixos com ênfase ao valor humano dado às águas.

\subsection{OS MITOS AMAZÔNICOS E CRENÇAS RELIGIOSAS}

As fontes hídricas sempre estiveram presentes nas vivências dos seres humanos ao longo de seu processo histórico, particularmente de modo diferenciado para as populações das águas, devido toda uma cultura de relações de aproximação que ditam, entre outros saberes, o de relacionar as águas com a religiosidade. As crenças voltadas para as águas permeavam intensamente nas populações tradicionais a sua relação com a divindade (DIEGUES, 2007).

Já sabemos que as crenças permearam as populações ao longo dos anos, fazendo existir na sociedade os mitos sobre as águas, nos mais diversos lugares, com as variadas denominações e versões historicizadas. Estes mitos ainda permanecem nas culturas da região amazônica, com destaque as populações que residem nas margens dos rios, furos 
e igarapés em sua rica e intensa diversidade cultural. Tais mitos se misturam aos contos, causos, saberes e encantos nestes lugares, como acontece nas águas dos rios Acará.

No município de Acará, existem variadas crenças e mitos que se vinculam às águas do rio Acará e estão presentes nas vivências cotidianas dos sujeitos. Destes, as que se relacionam com a religiosidade envolvem valores, afetos e crenças das pessoas voltadas a igreja católica, em especial tocam a Virgem Maria e os santos promotores de romarias, de novenas e de cultos. Portanto, fomentam-se simbolismos que são transmitidos e socializados por famílias. Assim, validam-se tais crenças e saberes. Para ilustrar, acontece anualmente o Círio Fluvial no rio Acará, dias antes do Círio oficial da cidade. Trata-se de uma procissão em que a imagem peregrina de Nossa Senhora de Nazaré é transportada na balsa acompanhada por outras embarcações com fiéis pelas águas atravessando algumas comunidades ribeirinhas. Durante o translado a imagem é homenageada por seus devotos com ritos de fé e devoção no conhecido Círio das Águas.

Os mitos amazônicos transitam nas cidades e alguns até se repetem, de certa forma caracterizando a região e a cultura amazônica paraense, como os comentados por residentes do entorno do rio Acará, o mito da Cobra Grande, do Curupira, da Mãe D’Água e do Boto que “[...] na cidade ainda é afirmado como o animal que, por encantamento, se torna homem e namora as mulheres da margem desse rio" (ALVES; POJO, 2020, p.53-54). Esses são narrados constantemente pela população local da cidade.

Como anteriormente mencionado, julga-se importante vincular esses conhecimentos alicerçados na cultura aos tópicos de problematização no espaço escolar, pois fazem parte da composição do aprendizado dos sujeitos e, de alguma forma, mobilizam a vida em suas aspirações e visões de mundo.

Assim, fazer interlocução entre crenças religiosas e mitos amazônicos e o ensino de ciências significa pautar uma realidade das águas vivida pelos sujeitos. Essa pode, ainda, ser problematizada sob alguns aspectos, por exemplo: a água como elemento de purificação, sua composição, sua influência na saúde dos sujeitos, na história e memória, na religião, no imaginário entre tantos outros simbolismos, todos esses aspectos fazem parte da cultura amazônica em sua dinâmica ancestral, portanto, esses 
saberes sobre as crenças religiosas e os mitos são parte da construção identitária desses sujeitos acaraenses.

Deste modo, pode-se ensaiar uma possível intersecção entre as crenças e mitos com ênfase no aprofundamento do eixo As águas e suas relações com as distintas culturas na Amazônia paraense. O ensaio visa aproximar os saberes das águas ao ensino de ciências, precisamente no que tange as culturas existentes, isto é, as dinâmicas contidas no espaço inter águas ${ }^{3}$ e de ações cotidianas no entorno do rio Acará. Essas permeiam na vida dos sujeitos o que justificariam os aprendizados em bases científicas, aqui priorizados por este ensino em diálogo com a cultura local produzida pelos sujeitos.

Esta proposição de mediar saberes, se relaciona com a afirmação de Freire (1996) sobre o ensinar-aprender, na medida em que possibilita a construção coletiva dos estudantes assentada em suas experiências e realidades diversas, gerador de múltiplos aprendizados.

\subsection{AFETO COM AS/PELAS ÁGUAS}

Apreciar, gostar, temer, valorar são alguns verbos que traduzem sentimentos de afeto pelas e com as águas; estão sempre presentes em depoimentos e nas vivências de sujeitos que cotidianamente realizam atividades laborais utilizando o curso das águas, em especial, dos que residem e/ou dependem do fluxo das águas dos rios, como barqueiros e pescadores. Em frente à cidade, percebe-se que muito da "Ação social (de trabalho, lazer, travessia, vizinhança, escola) é marcada pelo relógio natural impresso e expressado pelo movimento dos rios, responsáveis pelo vai e vem das pessoas" (POJO et al., 2014, p.190).

Além da utilização das águas para produção de sobrevivência, tem-se a realização de atividades domésticas nas águas, como: lavar louças e roupas e pegar água. Outrossim, há a realização de práticas esportivas e de lazer, por atletas e por moradores,

3 Termo que se refere ao movimento das pessoas e embarcações no trânsito por entre as águas, por exemplo, circulação nos espaços de rios ou igarapés, nos espaços das margens dentro de embarcações, nas beiradas e ilhargas dos trapiches e pontes. 
nos rios (banhos, passeios de canoa e brincares que acontecem nas águas próximos das pontes, por exemplo). Não obstante, deve-se levar em conta o constante ir e vir a urbis, a movimentação do rio por barqueiros ou moradores em deslocamentos diversos e diários. Assim, todas essas ações dão fluidez e circulação perene ao rio cujo envolvimento abarca crianças, adultos, idosos; visitantes, moradores e trabalhadores.

Tal fluidez e movimentação no rio Acará também se apresentam por dinâmicas próprias pelos sujeitos que a realizam, isto é, os sujeitos criam e estabelecem rotinas que envolvem horários, preços das travessias, afetos e trocas mútuas de trabalhadores. Um exemplo que pode ser mencionado são os barqueiros das balsinhas que realizam essa travessia constante de uma margem a outra, com pessoas que exercem suas ações tanto na cidade quanto no campo. Aproveita-se, então, desse ir e vir das pequenas embarcações para se transitar por esses lugares, construindo-se vínculos com estes barqueiros. Constituem-se, por conseguinte, formas distintas e comuns de materializar ações de navegação, de lazer, de comercialização, de realização de tarefas domésticas

entre outras, dando-se, logo, a integrada e fluída ancestralidade com a natureza das águas deste rio.

Aqui, cuidar das águas é a tônica, ou seja, são muitos os saberes, as apropriações e os valores que respaldam sentidos dos moradores desse cuidar. Paralelo a isso, na sociedade atual é um ato mandatário para nós humanos a exigência de saber cuidar, tendo em vista a sobrevivência dos seres vivos. Por isso, sugerimos a discussão no eixo

Cuidar das águas, agindo no ambiente. Busca-se, com isso, a abordagem da sustentabilidade ambiental de modo a proporcionar uma melhor compreensão e o incentivo à promoção de alternativas que respaldem um agir consciente, ecológico e de cuidado com as águas a partir da problematização de questões ambientais reais e do cotidiano dos sujeitos com esta fonte hídrica.

\subsection{PROCESSOS DES(EDUCATIVOS) E DE DEGRADAÇÃO DA}

\section{NATUREZA}

A flora, o solo e a água são elementos naturais e partem das dinâmicas sociais neste planeta, em especial, da vida humana e demais seres vivos, com isso, torna-se primordial o cuidado com esses elementos naturais. 
Assim, faz-se necessário aprofundar, com uma pedagogia do educar, o impacto das ações realizadas pelo homem na Terra e na natureza de modo geral, pois são perceptíveis os danos e consequências. No caso, cuidar da natureza ultrapassa os

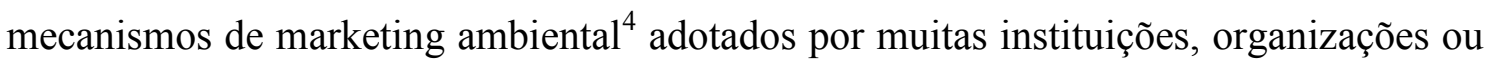
pessoas. Ao contrário, é central o desenvolvimento de ações de cuidado da natureza na linha do cotidiano da vida, das práticas culturais, das vivências, dos saberes, fluindo diariamente, nas atuações familiares, comunitárias e escolares de cuidado das fontes naturais.

Neste sentido, o entorno do rio Acará dita uma forma de natureza e de lidar com ela, na medida em que pelas águas desse rio são empreendidas ações de sujeitos que são da ordem do cuidado e de proteção e, em outras, são da ordem de causar malefícios. Ademais, a natureza do rio Acará abrange o conjunto de processos e produtos ali presentes: as águas, a paisagem com seus elementos (rua, casas, trapiches etc.), as travessias das embarcações, o lixo exposto em suas margens, os animais e pessoas transitando.

Assim, a construção desse olhar apurado durante observações no entorno do rio, torna possível a afirmação do processamento de conexões positivas e negativas com e nas águas. Dentre as positivas, citamos conversas e aprendizados informais, nos momentos de entretenimento às margens do rio e nas próprias ruas que acabam por refletir essa conexão dos sujeitos com a natureza desse lugar; contrastando, temos também ações negativas, como o contínuo despejo inadequado de resíduos no rio, nas ruas e no trapiche.

A figura abaixo é um exemplo do cruzamento entre a natureza, o cuidar e a água. Sendo partes de um mesmo ecossistema:

$4 \quad$ Diz respeito à ação social sustentável como algo corriqueiro, por exemplo, a empresa Hydro Alunorte, em Barcarena, no estado do Pará, tencionada por boas intenções para com o ambiente e o povo, vem causando prejuízos socioambientais e socioculturais de proporções gigantescas, são ações “[...] constituídas pela contaminação ambiental de rios, especialmente, por metais pesados bauxita e chumbo (rejeitos), cuja consequência é a precarização social de populações ribeirinhas [...]" (SILVA; GOMES, 2019. p.11). 


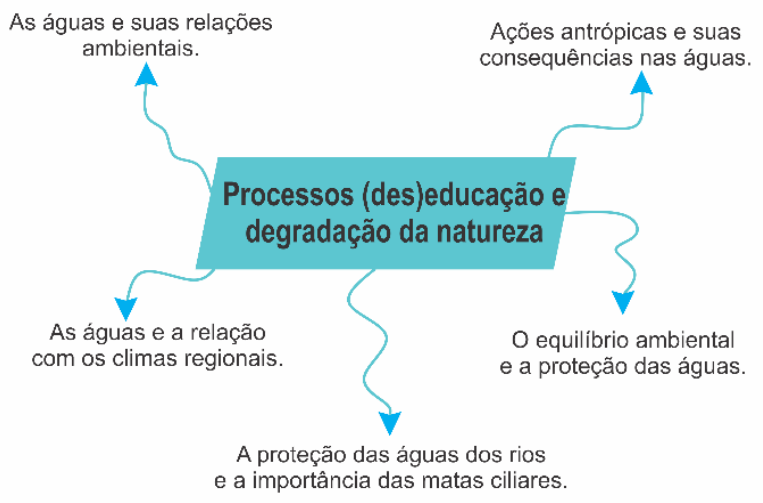

Figura 1 - A água e suas relações ambientais. Autoras, 2020.

Toda essa trama exposta na figura evidencia a possibilidade de trabalho do ensino de ciências focalizando o tema da (des)educação e a degradação da natureza a partir dos eixos elencados na figura acima. No qual articula-se por conter ações, dinâmicas e saberes relacionados às fontes naturais e que fazem parte do ecossistema. Sendo profícuo focalizar as características comuns, as localidades e as temporalidades das margens dos rios na prática educativa.

O ensino em sua prática vai além da mera apresentação dos aspectos naturais presentes, mas precisa problematizar a ação humana fazendo parte do ecossistema, sem contar na análise do espaço de convívio e nos contrastes de uma realidade social, ambiental e cultural.

O tema enfatiza também a discussão das influências diretas das ações dos sujeitos nas águas - seja de rios, córregos ou igarapés - que causam malefícios aos espaços, pois alteram significativamente suas características químicas, físicas e biológicas. No caso de um despejo inadequado de resíduos sólidos e líquidos nessas fontes hídricas. Deste modo, essa questão exige aprofundamento, tendo em vista suas consequências para o ecossistema e para a qualidade de vida das pessoas que residem neste lugar.

E, ainda, destaca-se a influência da água no clima local, regional e global, requerendo o debate dessa vertente coadunado à proteção e ao cuidado com as águas que se apresentam a partir do equilíbrio ambiental (uma vez que as águas estão dentro da composição desses ciclos naturais articulados com os ecossistemas do planeta, essenciais a existência humana). Com isso, como já sinalizado, há a necessidade de cuidado e de proteção da natureza, dos rios, córregos e igarapés. Em suma, de um ciclo 
de preservação da biodiversidade, detido aos espaços naturais, aos entornos das águas e aos locais de convívio com as pessoas que também exigem proteção e cuidado.

\subsection{OS SABERES DAS ÁGUAS PELA CULTURA LOCAL}

A cultura local é um potencial das gerações de seres humanos desde os primórdios. Neste sentido, as convivências entre sujeitos nos espaços naturais computaram uma diversidade de saberes locais cujas estruturas garantem a sobrevivência nesses lugares. Deste modo, "Essa adaptação a um meio ecológico de alta complexidade realiza-se graças aos saberes acumulados sobre o território e às diferentes formas pelas quais o trabalho é realizado" (CASTRO, 1998, p.06), tudo isso fruto da produção de cultura, constituída pelos sujeitos que "Ao transcender um mundo dado pela natureza e ao construir, material e simbolicamente um mundo de cultura [...]" afirmam-se "[...] como criador de suas próprias condições de existência e como sujeito da história" (BRANDÃO, 2017, p.394), a partir dos seus contextos e relações de convívio.

Com isso, o aprofundamento acerca das práticas exercidas nos locais faz-se fundamental, buscando compreender, em especial, o valor da cultura para composição do saber local, bastante atuante em comunidades tradicionais que vivem as margens de rios, com seus modos próprios de vida e vivências nas e com as águas. Ainda, ocorre a transmissão desse saber de modo informal e na convivência com os sujeitos sociais habitantes do lugar.

O saber local permeia a vida cotidiana, sendo gerador de muitos modos de ver, pensar e de agir no mundo, modos de estabelecimento de relações entre os sujeitos e a natureza, modos de interagir diante da atividade de trabalho, de uma ação cultural, da tradição, de se alimentarem, de se vestirem e, também, de aprenderem com as instituições escolares, ainda que nesses espaços o saber local passe às margens do currículo, em virtude disso, esse escrito é uma tentativa de elucidar possibilidades.

A água é um elemento de uso no cotidiano das pessoas e parte do saber local delas, logo muitas experiências e ações são praticadas com esta fonte de vida tornando-o visível seu potencial aprendizado em ciências, com a ressalva de uma discussão encharcada pelo contexto de inserção dos sujeitos. 


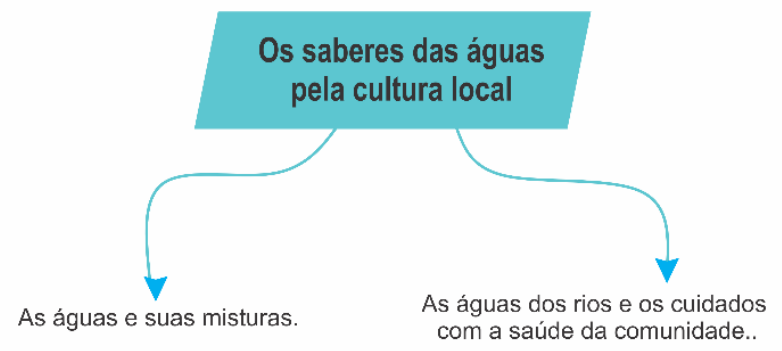

na figura abaixo:

Figura 2 - As águas e os cuidados com a saúde. Autoras, 2020.

Os eixos sinalizados na figura dialogam com os saberes presentes nos espaços das águas, que se encontram constantemente na vivência de qualquer sujeito e de modo singular dos residentes próximos aos rios e igarapés, como é o caso desta pesquisa. Eles e elas, pontualmente são potenciais aprendizes de cenários amazônicos - o que facilita o ensino de ciências, devido todo um cotidiano que mistura as águas e as atividades domésticas, de translado, de lazer e navegação sendo totalmente possível apreender sobre as misturas das águas, por um cunho mais científico.

Além disso, acredita-se na articulação desses saberes das águas com a cultura local como algo vital no sentido aqui discutido: o de se aprender sobre a água e como cuidar. Sendo basilar um olhar acerca da saúde comunitária, fruto das formas e relações com ela, com a água dos rios, sendo os indicadores de qualidade de vida propício para esse estudo e aprendizado.

\subsection{A ANCESTRALIDADE AMAZÔNICA E SUAS INTERTROCAS}

Segundo Brandão (2007), intertrocas dizem respeito à condicionantes econômicos ou produtos valorativos que traduzem uma movimentação simbólica e estruturada, significa dizer que essa mediação transcende as relações comerciais, “[...] na verdade são interpessoais, afetivas, sociais, simbólicas, antes ou ao lado de serem relações comerciais que envolvem dinheiro", se traduzem em "[...] sentidos de vida" de e entre 
sujeitos (BRANDÃO, 2007, p.55). Em comunidades ribeirinhas da região amazônica, como a do contexto onde ocorre a pesquisa, os sujeitos que residem no entorno do rio estão constantemente em contato com um conjunto de saberes das águas, com saberes da natureza, com saberes das marés, com relação de pares e vizinhos circulando nas práticas cotidianas e, ao mesmo tempo, se entrecruzando com elementos da urbanidade da cidade.

Outrossim, esses saberes das águas possuem uma história ancestral, ou seja, pessoas e lugares distintos produziram traços culturais que se manifestam, nesse caso, por meio de costumes, expressões corporais, tradições, ritos, símbolos que ainda hoje estão presentes ou estão em constante mudança, compondo assim essas intertrocas de saberes mediante esses fluxos contínuos exercidos nesses espaços e em partilha de humanos. Para ilustrar, os banhos de rio, os brincares nas águas e as atividades laborais e artesanais às margens vêm de longa data, sendo ainda presentes e fazendo parte das vivências das pessoas. Essas tradições e costumes traduzem um pouco de uma ancestralidade amazônica. Assim, as intertrocas de saberes das águas são uma condição ancestral herdada de indígenas, de negros e de demais habitantes que aqui chegaram, algo pontual de ser socializado no espaço escolar em relação com outras intertrocas científicas e contextualizadas nos tempos atuais.

$\mathrm{O}$ ensino de ciências articulado com as intertrocas dos saberes das águas potencializa mais uma vez, o reavivar das vivências cotidianas no sentido de seu valor ecológico, ambiental, cultural e científico. Sobre esta questão, Sasseron (2018) afirma que ao fazer o diálogo entre o ensino de ciências articulado ao saber dos estudantes estaremos "[...] desenvolvendo práticas científicas e epistêmicas em estreita relação com o desenvolvimento do raciocínio científico" (SASSERON, 2018, p.1068), estaremos construindo entendimentos palpáveis ao contexto dos alunos e da comunidade.

Analisar as ações que permeiam a realidade das localidades (em especial na região amazônica) com a majestosa influência hídrica em territórios ribeirinhos e com o conjunto de saberes das águas pode possibilitar um fortalecimento de vínculos afetivos e simbólicos dos sujeitos com estas fontes naturais. Dessa forma, o ensino de ciências cumpre seu papel: realizar intertrocas por meio de conhecimentos científicos, teóricos, práticos e metodológicos (sempre atrelando aos componentes curriculares basilares dessa área, as águas, os ecossistemas, a biodiversidade amazônica com suas florestas e 
dinâmicas socioculturais, por exemplo). Além mais, outra função desse ensino seria relacionar campos de saber presentes na vivência dos sujeitos, como está sendo o caso dos que vivem no entorno do rio Acará.

\section{CONSIDERAÇÕES FINAIS}

Neste escrito, buscou-se elucidar os aprendizados do espaço das águas pelos sujeitos residentes ou trabalhadores, do entorno do rio Acará. Para tanto, segue-se observações das vivências cotidianas em diálogo com possíveis eixos, temáticas e ensaios para e com o ensino de ciências. Pode-se perceber que as águas transitantes de rios, igarapés, furos, praias, córregos se conectam às vidas dos sujeitos do município de Acará, transmitindo um conjunto de saberes das águas cujos circuitos e intertrocas fazem-se notar nas travessias e suas movimentações, nos fazeres e nos convívios fluentes nesse espaço.

Assim, sinalizando dados preliminares com base na investigação, podemos dizer que os saberes das águas são de ordem prática na vida dos sujeitos e, simultaneamente, são possíveis de serem problematizados em uma prática educativa escolar na referida área. Neste aspecto, sobressaiu o saber local produzido pela cultura em movimento na localidade e que tais aspectos culturais e ambientais são ricos de informações, vivências e ações em relação à natureza das águas, que circulam nesse espaço.

Outra perspectiva da pesquisa a ser apontada, diz respeito às intertrocas de saberes. Essas foram alvo de observações in loco em dias, horários alternados e com pessoas distintas, dessa empreitada vimos que as intertrocas são construções sociais e de conhecimento, nos quais os saberes das águas possuem um valor afetivo por habitantes e trabalhadores do entorno do rio. Articular estes saberes com conhecimentos do ensino de ciências traz uma contribuição significativa para o fortalecimento da identidade dos sujeitos das águas, além do que pode suscitar o aprendizado, durante um dado tempo pedagógico, para um olhar e ação de cuidado para com esses espaços sociais, isto é, com os espaços das margens ou espaços ribeirinhos.

Pode também configurar-se em um aprendizado do lugar de convívio cotidiano (saber das águas) em estreita aproximação com o ensino de ciências, agora de um modo mais prático, isto é, articulada com o contexto local quando ensaiamos retratar eixos 
apresentados que trazem essa composição por serem as até aqui encontradas na pesquisa.

Olhar o rio ocasiona a percepção de uma travessia por saberes, a uma poética construída por aqueles habitantes e, ainda, para a questão política e de subsistência da vida, em relação à cidade e aquele entorno. Nesse entorno do rio Acará foi possível observar uma riqueza de aprendizados e opiniões, de saberes locais que, neste escrito, busca-se tematizar a construção de possibilidades de uma prática educativa e da construção de conhecimento no ensino de ciências.

\section{REFERÊNCIAS}

ALVES, Eliene da Silva; TOUTONGE, Eliana Campos Pojo. Saberes das águas intertrocas contínuas entre pessoas, saberes e uma fluida ancestralidade amazônica. In: Revista Falas Breves, Breves, PA, [S. v.], n. 8, p. 47-64, maio, 2020.

ALVES, D. dos S.; NASCIMENTO, F. L.; FALCÃO, M. T.; LIMA, R. C. P. de. Educação em espaços não formais: química e geografia - da sala de aula para o museu de solos de Roraima. Revista Insignare Scientia, RS, v. 3, n. 2, p. 237-256, 2020.

BRANDÃO, C. R. A educação como cultura. Memórias dos anos sessenta. Horizontes Antropológicos, Porto Alegre, RS, ano. 23, n. 49, p. 377-407, set/dez, 2017.

BRANDÃO, C. R. Tempos e espaços nos mundos rurais do Brasil. Ruris. Campinas, v. 1, n. 1 , p. 37-64, 2007.

CASTRO, E. Território, biodiversidade e saberes de populações tradicionais. In:

CASTRO, E.; PINTON, F. (Org.). Faces do trópico úmido: conceitos e novas questões sobre desenvolvimento e meio ambiente. Belém: CEJUP; UFPA-NAEA, 1998.

DIEGUES. A. C. Água e cultura nas populações tradicionais brasileiras. In: I Encontro Internacional: Governança da Água, São Paulo. Anais, São Paulo, 2007. p. 1-20.

FREIRE, P. Educação e Mudança. 12a . ed. Rio de janeiro: Paz e Terra, 1979.

FREIRE, P. Pedagogia da Autonomia: saberes necessários à prática educativa. $25^{\text {a }}$ ed. Rio de janeiro: Paz e Terra, 1996.

POJO, E. C. et al. As águas e os ribeirinhos - beirando sua cultura e margeando seus saberes. Abaetetuba. Revista Margens, Abaetetuba, v. 08, [S. n.], p. 176-198, 2014.

POJO, E. C. Gapuiar de saberes e de processos educativos e identitários na comunidade do rio Baixo Itacuruçá, Abaetetuba/PA. 2017. 243 f. Tese (Doutorado 
em Ciências Sociais) - Universidade Estadual de Campinas, Instituto de Filosofia e Ciências Humanas, Campinas, SP, 2017.

SASSERON, L. H.. Ensino de Ciências por Investigação e o Desenvolvimento de Práticas: Uma Mirada para a Base Nacional Comum Curricular. Revista Brasileira de Pesquisa em Educação em Ciências, UFMG, [S. v.], n. 18, p. 1061-1085, 2018.

SILVA, D. N. S. D.; GOMES, E. T. A. O uso da sustentabilidade como argumento legitimador da artificialização da natureza e do social no capitalismo contemporâneo. Revista em Pesquisa em Educação Ambiental, SP, v. 14, n. 2, p. 26-42, 2019. 